\title{
Flora da Bahia: Basellaceae
}

\author{
Davi Augusto Carneiro de Almeida ${ }^{{ }^{*}}$, Ana Maria Giulietti ${ }^{1,2}$ \& Reyjane Patrícia de Oliveira ${ }^{1}$ \\ ${ }^{1}$ Departamento de Ciências Biológicas, Universidade Estadual de Feira de Santana, Feira de Santana, Bahia, Brasil. \\ ${ }^{2}$ Herbarium, Royal Botanic Gardens, Kew, Reino Unido.
}

\begin{abstract}
Resumo - É apresentado o levantamento de Basellaceae para o estado da Bahia, Brasil. Foi encontrada unicamente a espécie Anredera cordifolia. São apresentadas descrições e comentários sobre a família, o gênero e a espécie, bem como ilustrações e o mapa da distribuição da espécie na Bahia.
\end{abstract}

Palavras-chave adicionais: Brasil, florística, Anredera.

\begin{abstract}
Flora of Bahia: Basellaceae) - A floristic survey of the Basellaceae from Bahia State, Brazil, is presented. We found only the species Anredera cordifolia. Descriptions and comments on the family, genus and species, as well as illustrations and a distribution map of the species in Bahia are presented.
\end{abstract}

Additional key words: Brazil, floristics, Anredera.

\section{BASELLACEAE}

Ervas perenes, escandentes ou trepadeiras, geralmente suculentas, comumente apresentando tubérculos. Folhas simples, alternas ou menos frequentemente opostas, pecioladas ou sésseis, inteiras ou raramente apiculadas e denteadas, sem estípulas. Inflorescências com espigas axilares ou terminais, racemosas ou paniculadas, persistentes, indeterminadas ou pseudodeterminadas. Flores pouco vistosas, bissexuadas ou raramente unissexuadas, actinomorfas, períginas, monoclamídeas, com um par de bractéolas na base do cálice, semelhantes às sépalas, livres ou unidas entre si, prefloração imbricada; cálice (4)5(-13)-mero, petaloide, branco ou avermelhado, gamossépalo ou raramente dialissépalo; estames (4)5(-9), opostos às pétalas, filetes frequentemente adnatos ao cálice; anteras rimosas ou poricidas; disco nectarífero presente ao redor do androceu; ovário súpero, carpelos 3, sincárpico, lóculo 1 , óvulo 1 , placentação ereta; estiletes 3, unidos ou livres, estigmas 3. Fruto drupa, frequentemente cercado por bractéolas e perianto persistentes; sementes globulares, testa membranosa, endosperma conspícuo, embrião espiralado ou semicircular.

Basellaceae apresenta distribuição pantropical e inclui aproximadamente 20 espécies distribuídas em quatro gêneros (Anredera Juss., Basella L., Tournonia Moquin-Tandon e Ullucus Caldas), dos quais apenas Anredera é nativo no Brasil, com três espécies. Basella alba L. é nativa do Velho Mundo e cultivada no país como hortaliça (Souza \& Lorenzi 2005; Bastos \& Sakuragui 2010).

\footnotetext{
*Autor para correspondência: daviaugusto@gmail.com

Editor responsável: Julio Lombardi

Submetido: 7 jan. 2013; aceito: 3 jun. 2013

Publicação inicial: 7 ago. 2013; versão final: 2 maio 2014
}

Anredera Juss.

Ervas escandentes, suculentas, ramificadas. Folhas sésseis ou pecioladas, levemente carnosas. Inflorescências em racemos axilares ou terminais, raramente ramificados. Flores bissexuadas ou funcionalmente unissexuadas, pediceladas; pedicelos persistentes, articulados abaixo do perianto, bractéolas em 2 pares, decussadas, adnatas ao perianto, bractéolas inferiores pequenas, conadas, persistentes ou livres, efêmeras, bractéolas superiores tepaloides, convexas, frequentemente quilhadas abaxialmente, estreitamente ou raro largamente aladas; sépalas estreitas, membranosas, conadas na base, brancas, amareladas a avermelhadas; filetes filiformes, expandidos em direção à base, recurvados no ápice; estiletes 3-partidos, estigmas globulares ou claviformes, papilosos. Fruto ovoide ou globoso, completa ou parcialmente fechado pelo perianto seco, pericarpo carnoso.

Ocorre dos Estados Unidos até a Argentina, sendo que a maioria das espécies ocorre na América do Sul (Sperling \& Bittrich 1993). No Brasil, foram registradas três espécies: $A$. cordifolia (Ten.) Steenis, A. marginata (Kunth) Sperling e A. tucumanensis (Lillo \& Hauman) Sperling (Udulutsch et al. 2007).

Anredera cordifolia (Ten.) Steenis, Fl. Males., Ser. 1, Spermat. 5(3): 303. 1957.

$=$ Boussingaultia baselloides Kunth in Humboldt, Bonpland \& Kunth, Nov. Gen. Sp. (quarto ed.) 7: 196. 1825.

= Boussingaultia cordifolia Ten., Ann. Sci. Nat. Bot., sér. 3, 19: 355. 1853.

= Boussingaultia gracilis Miers, J. Bot. 2: 161. 1864.

Figuras $1 \mathrm{~A}-\mathrm{G}$ e 2 .

Trepadeiras revolutas. Pecíolo 1-3,5 cm compr.; lâmina foliar ovada a subcordada, 4,5-18,5 × 3-10 cm, pouco carnosa, base arredondada, ápice obtuso a retuso, glabra em ambas as superfícies, produzindo pequenos tubérculos axilares (bulbilhos). Inflorescências em racemos densos; raques pendentes, 

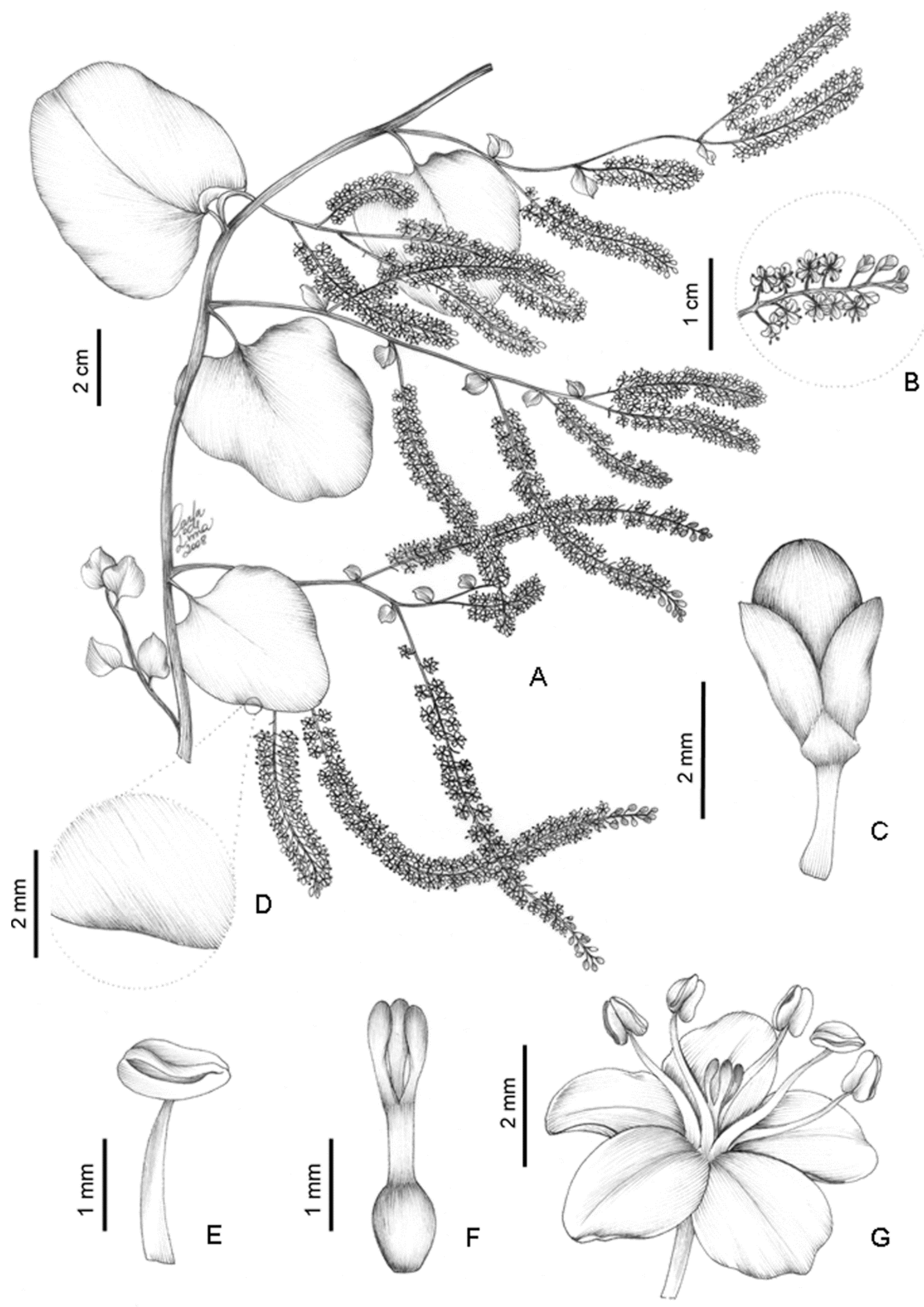

Figura 1. Anredera cordifolia: A- ramo fértil; B- ápice do racemo; C- botão floral; D- borda da folha; E- estame; F- pistilo; G- flor (Harley 53915 ). 


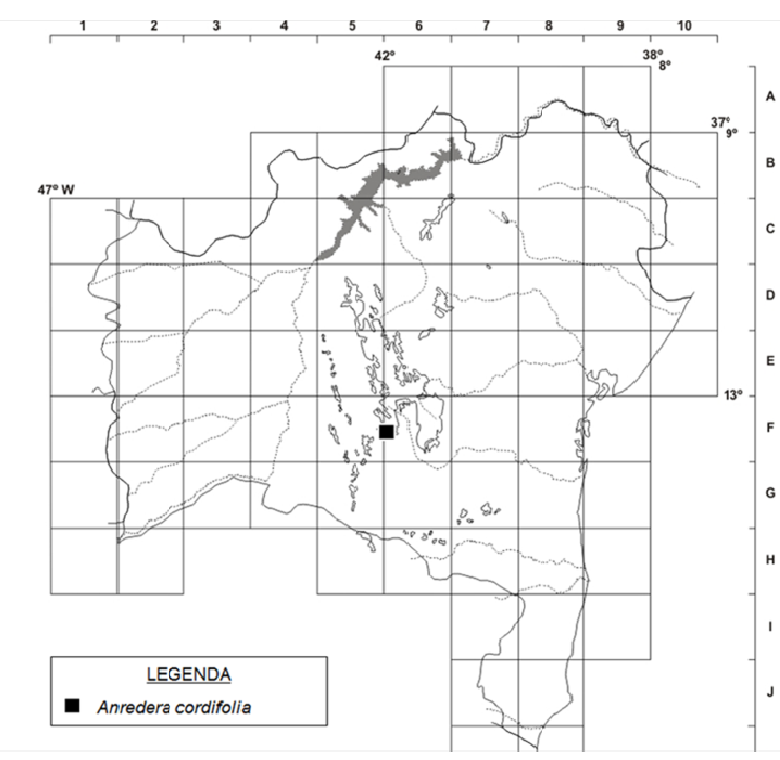

Figura 2. Mapa de distribuição de Anredera cordifolia no estado da Bahia.

delgadas, 3-20 cm compr.; brácteas curtas, estreitas, 1-2,5 x ca. 1,5 cm; pedicelos 2-3 mm compr. Flores 4-5 mm diâm., perianto branco; estames brancos; estiletes 3 , divididos até a metade, cada ramo com um 1 estigma claviforme. Frutos e sementes não vistos.

Espécie com distribuição principalmente neotropical, ocorrendo do sul dos Estados Unidos à Argentina (Udulutsch et al. 2007). Sua ocorrência no Brasil foi registrada nos estados do Espírito Santo, Paraná, Santa Catarina, São Paulo (Udulutsch et al. 2007) e Rio Grande do Sul (Bastos \& Sakuragui 2010). Na Bahia, restringe-se ao município de Rio de Contas: F6. Foi encontrada fértil em maio.

Material examinado - Rio de Contas, $13^{\circ} 33^{\prime} \mathrm{S}, 41^{\circ} 57^{\prime} \mathrm{W}$, maio 2000, R.M. Harley \& A.M. Giulietti 53915 (CEPEC, HUEFS).

Material adicional examinado - BRASIL. PARANÁ: Guaratuba, fev.1989, J.M. Silva \& G. Hatschbach 568 (HUEFS); São José dos Pinhais, fev.1985, G. Hatschbach 48950 (HRB).

É facilmente reconhecida pelas inflorescências em racemos, flores diminutas e folhas ovadas a subcordadas. Propagam-se vegetativamente através dos bulbilhos axilares, os quais, assim como as folhas e raízes, são utilizados medicinalmente (Dequan \& Gilbert 2003).

\section{Agradecimentos}

Aos curadores dos herbários, pelo acesso às coleções e à Carla de Lima pelas ilustrações. Ao CNPq e FAPESB, pelo auxílio financeiro aos projetos Flora da Bahia e PROTAX (FAPESB APR 162/2007; CNPq Proc. 562278/2010-9 e 483909/2012). À CAPES, pela bolsa de mestrado concedida ao primeiro autor, e ao CNPq, pelas bolsas de produtividade em Pesquisa PQ1-A e PQ2 concedidas a AMG e RPO, respectivamente.

\section{REFERÊNCIAS}

Bastos, F. \& Sakuragui, C.M. 2010. Basellaceae. In: R.C. Forzza, J.F.A. Baumgratz, C.E.M.Bicudo, A.A. Carvalho Jr., A. Costa, D.P. Costa, M.Hopkins, P.M. Leitman, L.G. Lohmann, L.C. Maia, G. Martinelli, M. Menezes, M.P. Morim, M.A. N. Coelho, A.L. Peixoto, J.R. Pirani, J. Prado, L.P. Queiroz, V.C. Souza, J.R. Stehmann, L.S. Sylvestre, B.M.T. Walter \& D. Zapp (eds). Catálogo de Plantas e Fungos do Brasil. Vol. 1. Instituto de Pesquisas Jardim Botânico do Rio de Janeiro, Rio de Janeiro.

Dequan, L. \& Gilbert, M.G. 2003. Basellaceae, In: W. Zheng-Yi \& P. Raven (eds), Flora of China: Ulmaceae-Basellaceae, Vol. 5. Missouri Botanical Garden Press, Saint Louis, p. 445-446.

Souza, V.C. \& Lorenzi, H. 2005. Basellaceae. Botânica Sistemática: guia ilustrado para identificação das famílias de angiospermas da Flora Brasileira, baseado em APG II. Instituto Plantarum, Nova Odessa, p. 238.

Sperling, C.R. \& Bittrich, V. 1993. Basellaceae. In: K. Kubitzki, J.G. Rohwer \& V. Bittrichm (orgs), The Families and Genera of Vascular Plants, Flowering Plants, Dicotyledons: Magnoliid, Hamamelid and Caryophyllid families. Vol. 2. Springer-Verlag, Berlin, p. 143-146.

Udulutsch, R.G.; Dias, P.; Pinheiro, M.H.O. \& Furlan, A. 2007. Basellaceae. In: M.G.L. Wanderley, G.J. Shepherd, A.M. Giulietti, T.S.A. Melhem \& M. Kirizawa (orgs), Flora Fanerogâmica do Estado de São Paulo. Vol. 5. Instituto de Botânica de São Paulo, São Paulo, p. 17-20. 